\section{COMUNICACIÓN RESPONSABLE DE UNA MARCA TURÍSTICA EN CRISIS: EL CASO DE VILLA LA ANGOSTURA EN LA ERUPCIÓN DEL VOLCÁN PUYEHUE}

Andrea F. Gutauskas ${ }^{1, *}$ y Raquel Valdez ${ }^{1}$

\section{RESUMEN}

La imagen de marca de un destino turístico es la percepción global que el turista posee del mismo en base a lo que conoce, cree y siente. Tal imagen es compleja, especialmente al hablar de destinos, y no es estática, puede cambiar ante noticias de crisis. Frente a estas situaciones críticas, los destinos pueden aplicar la resiliencia como capacidad adaptativa. El estudio utilizó una triangulación metodológica cualitativo-cuantitativo, analizando las comunicaciones de la marca del destino turístico Villa la Angostura, o VLA, frente a la erupción del volcán Puyehue en 2011. La investigación permitió caracterizar la comunicación de la situación de crisis en distintos medios de comunicación junto a personas y organizaciones involucradas con la imagen y su resiliencia. Como conclusión, la imagen de marca del destino VLA logró sobreponerse a la crisis y hoy parece incluso más fuerte. En este proceso de resiliencia de la marca se destaca una activa participación de los actores del destino, la reconstrucción de su imagen y la necesidad de que los destinos turísticos incorporen planes de gestión de crisis con un plan de comunicación concreto y responsable en pos de una restauración efectiva de la imagen.

\section{PALABRAS CLAVE}

Marca, Crisis, Resiliencia, Villa la Angostura, Argentina

RESPONSIBLE COMMUNICATION OF TOURISM BRAND DURING CRISES: THE CASE OF VILLA LA ANGOSTURA IN THE PUYEHUE VOLCANO ERUPTION

\section{ABSTRACT}

The brand image of a tourist destination is a global perception that tourists possess on what they know, believes, and feel about it. The image of a brand is complex, especially for destinations. It is not static and can change depending on the communications during crises and disasters. In contrast, destinations can apply resilience as an adaptive capacity. The study's methodology uses a qualitative-quantitative triangulation to analyze brand-imagen communications of the destination Villa la Angostura or VLA, Argentina, during the Puyehue volcano eruption in 2011. The research systematizes crisis communications on different media outlets, and brand-image resilience from marketing practitioners. As conclusion, the brand image of the destination VLA managed to recover from the volcanic crisis, seeming stronger today. In the resulting process of resilience, three elements are outlined: the active participation of all destination's actors; an effective reconstruction of the brand-image; and the necessity of better preparedness measures from tourist destinations, such as crisis management plans that incorporate responsible communication.

\section{KEYWORDS}

Brand, Crisis, Resilience, Villa la Angostura, Argentina
1. Facultad de Turismo, Universidad Nacional del Comahue, Neuquén, Argentina.

*Autor de correspondencia: andregutauskas@hotmail. com

\section{RECIBIDO}

13 de octubre de 2018

\section{ACEPTADO}

28 de noviembre de 2018

\section{PUBLICADO}

1 de enero de 2019

\section{Formato cita}

Recomendada (APA): Gutauskas, A. F. y Valdez, R. (2019). Comunicación responsable de una marca turística en crisis: El caso de Villa la Angostura en la erupción del volcán Puyehue, Revista de Estudios Latinoamericanos sobre Reducción del Riesgo de Desastres REDER, 3(1), pp.53-68.

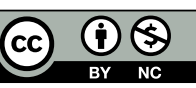

Todos los artículos publicados en REDER siguen una política de Acceso

Abierto y se respaldan en una Licencia CreativeCommons Atribución-NoComercial 4.0 Internacional.

\section{Revista de Estudios}

Latinoamericanos sobre Reducción del Riesgo de Desastres (REDER)

Diseño: Lupe Bezzina Tipografía: Hospital 


\section{INTRODUCCIÓN}

La imagen de marca de un destino turístico con un fuerte posicionamiento en el mercado puede verse afectada por una situación de crisis de diferente naturaleza, conocer las acciones de comunicación de los actores del destino' ante dicha crisis ayuda a establecer protocolos de acción frente a nuevas crisis e incluso a otros lugares con problemáticas similares. La imagen de marca se refiere a la idea o reflejo que tiene el público sobre el destino teniendo como base: qué sabe o ha escuchado de sus características, sus cualidades específicas, su identidad. Es el reflejo externo captado por el público. La imagen se torna entonces en una característica inteligible, sugestiva y cómplice entre el destino turístico y su público (Valls, 2003). Los autores Echtner et al. (2003) mencionan que el proceso de formación de la imagen turística es complejo, múltiple en elementos y procesos. Los autores Gartner y Hunt (1987) agregan que se trata de algo relativo, subjetivo, comparativo y dinámico en tiempo y espacio.

Así, la imagen no es algo estático, sino que evoluciona en función de los estímulos que reciben las personas. Un suceso crítico externo al destino, como puede ser algún evento climático, geológico, geográfico o social, produce dificultades para la actividad turística de múltiples maneras. La imagen de una marca turística, construida luego de años de gestión entre actores públicos y privados, puede verse rápidamente dañada por este tipo de eventos (Evans \& Elphick, 2005). Es en estas situaciones cuando la comunicación responsable, en tanto una de las herramientas del marketing responsable ${ }^{2}$, juega un rol fundamental, como así también la resiliencia como capacidad de un socio-ecosistema, impactado por algún tipo de crisis, para regenerarse a sí mismo sin afectar su forma y funciones: lo que llamaremos aquí también 'conservación creativa' (Escalera R. \& Ruiz B., 2011). Escalera R. y Ruiz B. (2011) encuentran complementariedad en la responsabilidad social empresarial y la resiliencia para construir un nuevo tipo de organización orientada a la creación de valor sostenible, vinculada directamente a su capacidad de perdurar en el tiempo y de crear a la vez valor económico, social y ambiental. Los gestores del destino turístico deben organizarse y valerse de las herramientas del marketing y, especialmente, del marketing responsable, para revertir dicha situación y restablecer la imagen de marca del destino.

El presente trabajo presenta la versión final del estudio de las comunicaciones del destino Villa la Angostura antes, durante y luego de la erupción del volcán Puyehue en 2011, cuyo primer avance fuera presentado por parte de las autoras en el VI Congreso Latinoamericano de Investigación Turística CLAIT (Gutauskas \& Valdez, 2014).

\section{CONTEXTUALIZANDO EL ESTUDIO DE CASO}

VLA es un destino turístico de la Patagonia argentina ubicado en el sur de la provincia del Neuquén sobre la margen norte del lago Nahuel Huapi, a $42 \mathrm{~km}$. del límite con Chile, con el que se comunica a través del Paso Internacional Cardenal Samoré de importancia para el movimiento económico y turístico de la región. Es una villa turística rodeada de bosque nativo, con una población de 11.063 habitantes (INDEC, 2010). Según datos del informe Presentación Plan de Recuperación integral de VLA de junio 2011 (Mesa de acuerdo para la Sustentabilidad de VLA, 2011), este destino contaba en 2009 con 4.158 plazas hoteleras habilitadas en 142 establecimientos hoteleros, 96 prestadores gastronómicos y 86 servicios turísticos. De acuerdo a una estimación anual, en 2010 los turistas que durmieron en hoteles, hosterías, cabañas habilitadas ascendían a 487.334 y en alojamientos informales sumaban 125.000. Con una ocupación media anual del 34,64\%. El empleo mensual estimado era de 700 puestos de trabajo en alojamientos turísticos y 1.600 en comercios y servicios

Hacia 2011, el 4 de junio, la erupción del complejo volcánico Cordón Caulle alteró la actividad turística de VLA (ver Figura 1). El volcán Puyehue ${ }^{3}$ se ubica en Chile a una distancia de 36 km de VLA. Luego de la erupción, la acción de los vientos del océano Pacífico condujo la nube de arena y cenizas volcánicas hacia Argentina, lo que trajo aparejados problemas ambientales y económicos para las localidades más cercanas, tanto turísticas como agrícola-ganaderas, además de tener un impacto directo sobre los ecosistemas de la región. Los destinos de la provincia del Neuquén más afectados fueron: Villa la Angostura, Villa Traful, San Martin de los Andes, Junín de los Andes y Neuquén capital, todos en diferentes formas (NeuquenTur, 2012).

VLA quedó sepultada bajo un manto de $30 \mathrm{~cm}$ de ceniza volcánica, lo que trajo como consecuencia la interrupción temporal de los servicios básicos, suspensión de las actividades públicas, como así también del turismo. La actividad turística fue muy baja durante los meses de junio, julio y
1. Se denomina actores del destino, a las organizaciones del sector público y privado, a la comunidad loc turistas y otras organizaciones n lucrativas del destino.

2. El 'marketing responsable' intenta optimizar los impactos de las actividades asegurando un equilibrio sostenible entre beneficios económicosy tenible entre beneficios economicos y tales (Rossi, 2010)

3. El volcán Puyehue forma parte del cordón Caulle (ubicado en la República de Chile) 
agosto de 2011. La ocupación hotelera cayó a niveles impensados, alcanzando solo el 15\%. Todos los números de la temporada de invierno 2011 fueron negativos; fue el peor año de la historia turística del destino. Los indicadores mejoraron hacia el primer semestre de 2012, aumentando la cantidad de turistas que llegaron al destino como los índices de ocupación hotelera. Según estimaciones oficiales, el turismo en la provincia del Neuquén se resintió en la temporada de verano 2011-2012, siendo un $41 \%$ menos que en los mismos períodos de años anteriores. También se vieron afectadas las comunicaciones y la vinculación terrestre con Chile, ya que el paso fronterizo estuvo cerrado temporalmente.

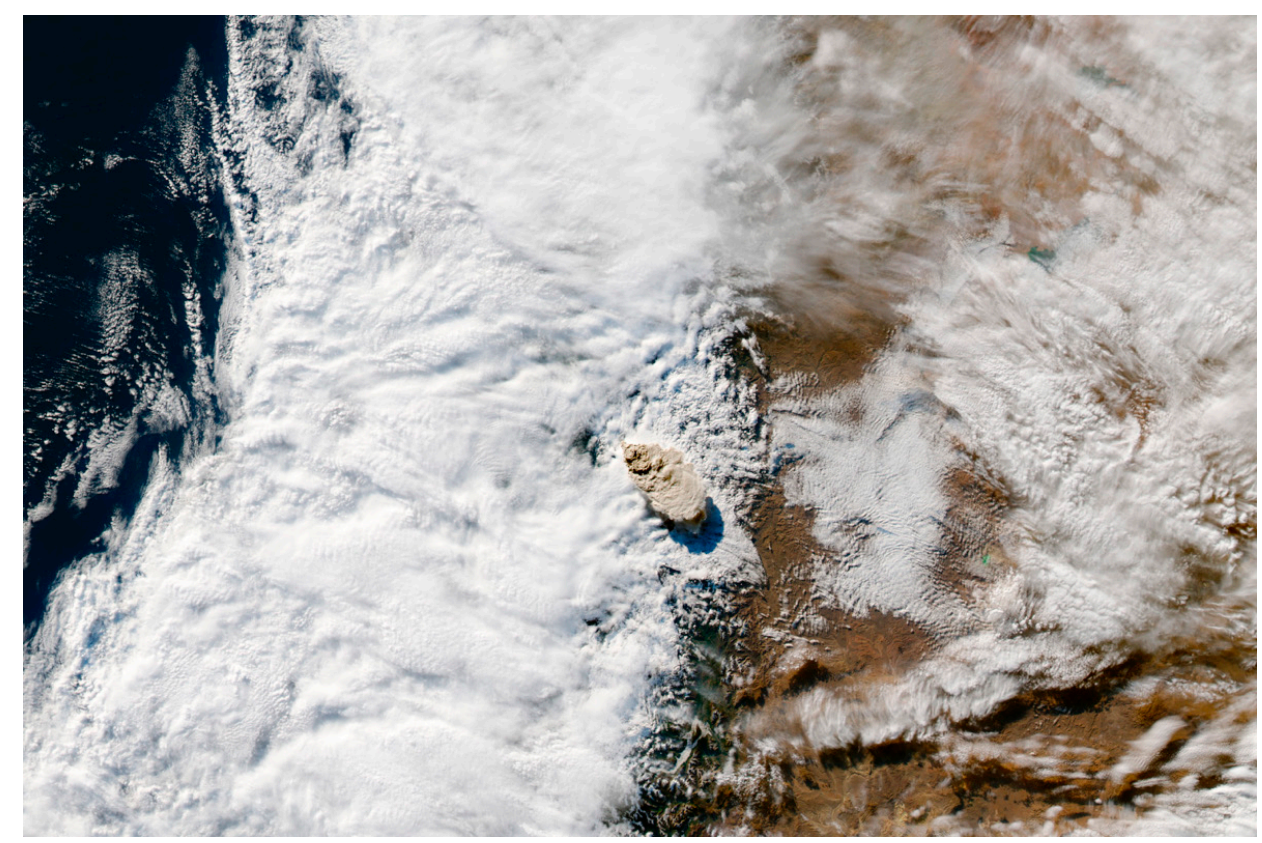

Figura 1. Imagen satelital de la explosión del complejo volcánico Puyehue-Cordón Caulle Fuente: NASA's Earth Observing System, 2011

Según el Gobierno de la Provincia del Neuquén, el impacto de la erupción volcánica en la provincia generó pérdidas por más de $\$ 65$ millones de pesos argentinos (ARS) en distintos rubros. Los establecimientos hoteleros del destino, casi en su totalidad ( 150 hoteles), debieron suspender sus actividades. La economía local se vio fuertemente afectada, ya que más de 100 comercios cerraron durante los meses más críticos (junio, julio y agosto) y un 30\% de ellos cerró de forma definitiva.

A esta situación se sumó que, durante los primeros días de la erupción, VLA estuvo presente en las noticias de la mayoría de los diarios nacionales y regionales en Argentina, que la describían como una verdadera zona de desastre.

El objetivo general de la investigación es describir y analizar las comunicaciones de la imagen de marca y la percepción de ella por parte de los turistas reales y potenciales del destino VLA frente a una situación crítica (erupción del volcán Puyehue), identificando a los actores involucrados en su comunicación. Para contestar a la pregunta, realizamos las siguientes acciones: 1) Identificar las acciones de comunicación que se realizan desde el destino durante y luego de la situación de crisis; 2) Identificar los principales actores (sector público, privado y comunidad) involucrados en las comunicaciones de un destino turístico, incluyendo factores de la resiliencia de la marca VLA; 3) Conocer la percepción de la imagen de marca del destino del mercado actual y potencial luego de la crisis. Algunas de las interrogantes que dilucidaremos más adelante y que nos ayudarán a comprender mejor el proceso por el cual atravesó la imagen de marca durante la crisis son: ¿Cómo era la imagen del destino VLA previa a la situación de crisis? ¿Se vio afectada la imagen de VLA por las comunicaciones de la erupción del volcán y sus consecuencias en el destino? ¿Influyen psicológicamente las malas noticias en la elección de un destino vacacional? ¿Qué personas y organizaciones están involucradas en las acciones de comunicación de una situación de crisis de un destino turístico? ¿Cómo deberían ser gestionadas las comunicaciones ante una situación crítica?, entre otras.

\section{ENTIENDO LA PROBLEMÁTICA DE LA GESTIÓN DE CRISIS EN EL SECTOR TURISMO}

En cuanto a los antecedentes académicos acerca de situaciones de crisis que afectan al turismo a 
nivel mundial, el estudio de revisión bibliográfica realizado por Pforr (2006) indica que, a pesar de un aumento en las investigaciones del tema, existe una falta considerable de claridad en relación con los impactos de las crisis sobre el turismo. Ritchie (2004) y Faulkner (2001) describen la necesidad de una planificación proactiva y la puesta en práctica de estrategias como la supervisión y evaluación de resultados. Pforr (2006) hace hincapié en que la vulnerabilidad del turismo a acontecimientos externos hace necesaria la incorporación de la gestión de crisis en las operaciones tanto del sector público como privado.

Pforr (2006) menciona otro tema que se repite en la literatura, el importante papel de los medios de comunicación en la crisis después de un acontecimiento desastroso, señalando su influencia psicológica a la hora de elegir opciones de viaje. Otro tema importante, señalado por Faulkner (2001) y Madrid Peralta (2011), este último a través de una investigación que comparó diferentes experiencias internacionales exitosas de reconstrucción de destinos afectados por desastres y situaciones de crisis, es que concuerdan en que la prevención de crisis y las tareas de restauración necesitan del esfuerzo integrado entre el sector público y privado.

Un destino turístico es entendido como un conjunto de productos turísticos que interactúan en una demarcación geográfica específica y a los que hay que sumarle factores como el clima, la infraestructura, los servicios y los recursos naturales y culturales (Valls, 2003). Serra Cantallops (2002) incorpora a este concepto dos componentes esenciales: la imagen y los precios. El destino se convierte así en un producto en sí mismo, por lo tanto, puede promocionarse. En síntesis, el destino está conformado por elementos tangibles -una localización geográfica con propiedades físicas, espaciales-e intangibles -como unidad sociocultural.

Bigné, Font y Andreu (2000) aclaran que los destinos son elementos complejos percibidos subjetivamente: se trata de combinaciones de productos turísticos que representan una experiencia integrada a los turistas. Tradicionalmente, los destinos se consideraban como una zona bien definida geográficamente, como un país, una isla o una ciudad. Sin embargo, cada vez más se reconoce que un destino puede ser un concepto percibido, es decir, que puede interpretarse subjetivamente por los consumidores en función de sus itinerarios de viaje, su formación cultural, el motivo de la visita, el nivel de educación y la experiencia previa. Estos autores también mencionan que el marketing de los destinos turísticos debe ser una herramienta para conseguir sus objetivos estratégicos reconociendo que, para ello, es necesario analizar la rueda dinámica de los actores en la que se representan cada uno de los intereses particulares, como así también los beneficios buscados. Por tanto, la concreción de los objetivos estratégicos de un destino dependerá de la relación entre dichos actores (ver Figura 2). Además, estos autores, haciendo referencia a Buhalis (2000), identifican a 5 actores del destino:

- El sector público: agrupando organismos públicos municipales o internacionales

- El sector privado: constituido por las empresas turísticas de todos los rubros

- La comunidad local del destino turístico

- Los turistas

- Las organizaciones no lucrativas que actúan en el destino

El marketing de los destinos turísticos debe ser utilizado como un 'mecanismo estratégico' entre la planificación y la gestión. En este sentido, los organismos públicos de turismo deben propiciar la planificación integrada de las actividades que inciden en el destino y también gestionar la imagen de marca de este en una actividad compartida entre todos los actores involucrados.

La imagen de un destino es percibida por su público y es definida como la noción formada a través de la interpretación razonada y emocional del turista (Tamagni et al., 2010). Esta imagen percibida es la consecuencia de la combinación de dos componentes: el perceptual cognitivo, que se refiere a las creencias $u$ opiniones y conocimientos o saberes que tienen los individuos sobre el destino - llamadas 'evaluaciones de los atributos'- y el perceptual afectivo, que hace referencia a los sentimientos que los turistas tienen en función de lo que saben o conocen del destino, es decir, la "respuesta emocional" que los individuos enuncian de un determinado lugar (Beerli \& Santana, 2003). 


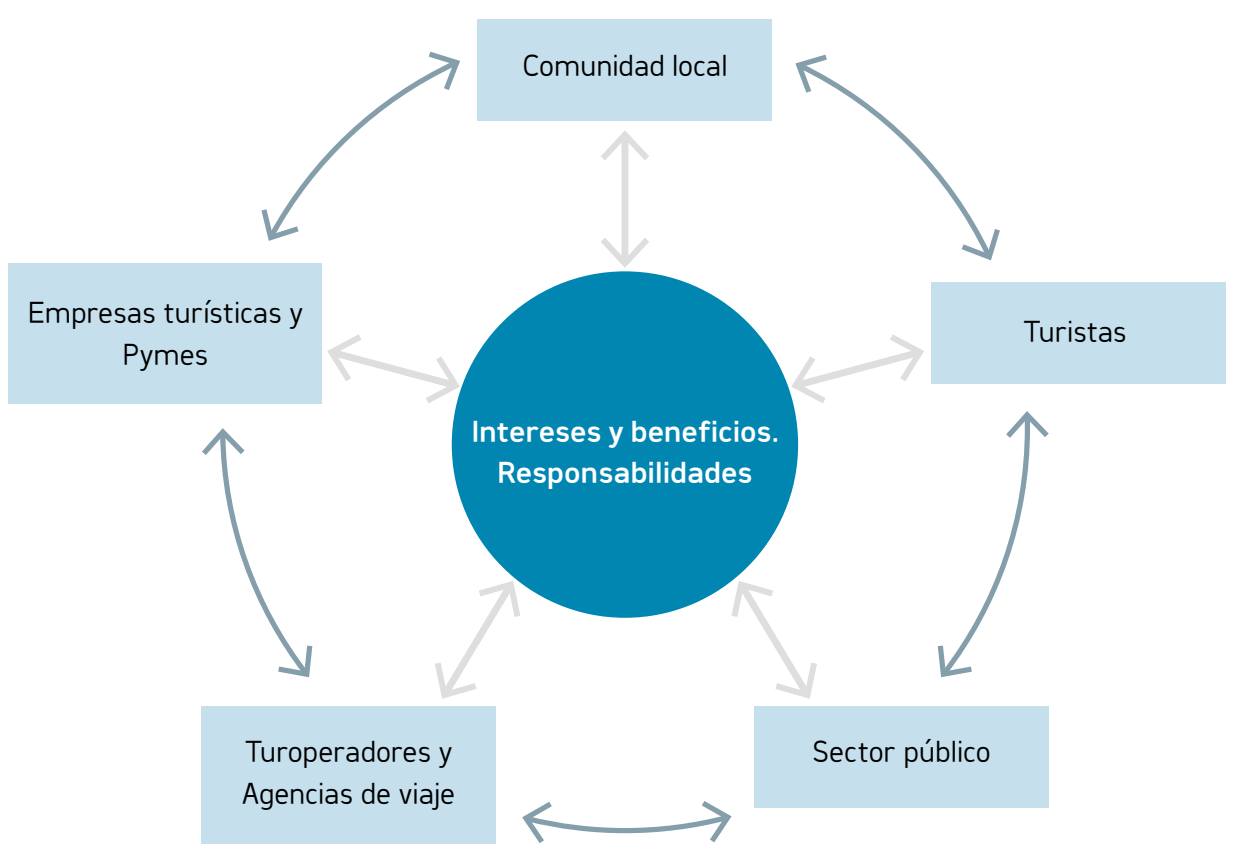

Figura 2. La rueda dinámica de los participantes en el destino turístico Fuente: Buhalis (2000) en Bigné et al. (2000)

Gartner (1993) enuncia como agentes de conformación de la imagen de un destino, la siguiente clasificación:

- Inducido abierto: corresponde a las formas convencionales de publicidad en los diferentes medios de comunicación -televisión, radio, medios impresos, Internet, etc. -. Los emisores de estos mensajes son de dos tipos: las organizaciones responsables de la comunicación de destino y las empresas privadas del mismo.

- Inducido encubierto: es la utilización de personajes famosos o celebridades en las actividades de promoción del destino.

- Autónomo: incluye a los medios de comunicación que transmiten noticias, documentales, reportajes, películas. La información que se proyecta a través de estos agentes puede clasificarse en noticias y cultura popular. La emisión de noticias tiene un impacto muy importante en la formación de la imagen de un destino, es la que ejerce mayor influencia en el cambio de imagen del mismo. El autor también menciona que si el evento emitido es de gran trascendencia posiblemente la imagen del destino se vea modificada a corto plazo y que, si existe una ausencia de un reforzamiento de la imagen previa, los efectos pueden ser negativos.

- Orgánico: constituido por las personas, parientes, amigos y conocidos que transmiten información de los destinos en base a su conocimiento o experiencia. También llamada publicidad 'boca-oído'.

- Visita al destino: es el punto final del proceso de conformación de la imagen de un destino.

Gartner (1994) destaca que la principal diferencia entre los agentes que contribuyen a la formación de las imágenes orgánica e inducida es el grado de control que ejerce el destino sobre los mismos. La imagen orgánica se caracteriza por una ausencia de control en la información emitida por los actores del destino -como agentes de conformación de imagen- mientras que, contrariamente, la formación de la imagen inducida resulta controlada por los promotores del destino turístico.

Las marcas turísticas poseen dos dimensiones esenciales: una cultural, relacionada con la identidad del lugar, 'marca conceptual', y otra visual y comunicativa, que busca transmitir a través de signos, símbolos, palabras, colores, 'marca gráfica'. Valls (1992) menciona que la sinergia entre 
ambas, es decir, la fortaleza del concepto esencial transmitido por la marca, potencia el reconocimiento y posicionamiento generando 'imagen de marca'. Aquí es importante comprender el carácter no estático de la imagen de marca de un destino sino más bien dinámico y fluctuante en el tiempo, sobre todo ante la influencia del accionar de los distintos agentes de formación durante sucesos no controlables para el destino como son las situaciones de crisis.

Por otra parte, la comunicación de los destinos turísticos permite, a través del uso coordinado y conjunto de elementos de comunicación (publicidad, promoción de ventas, relaciones públicas, patrocinio) contribuir a la construcción de una identidad propia del destino y a la proyección hacia el mercado de la adecuada imagen del mismo (Bigné et al., 2000), para lo cual se debe trabajar en forma coordinada entre los distintos actores (sector público, empresas del sector turístico, comunidad local y turistas) del destino para lograr una comunicación acertada.

La comunicación, tanto interna como externa, vinculada al concepto de marketing responsable, debe adaptarse a los nuevos criterios. Se debe pensar hacia dónde y en qué sentido se dirige, es decir, la comunicación estará referida a captar la atención del cliente no solo con las características del producto/servicio sino más bien a los beneficios sociales, económicos y culturales que brinda. Dentro de este marco comienza a configurarse la responsabilidad social corporativa (RSC), la cual se corresponde con la ética de la acción y de la responsabilidad por las consecuencias inmediatas y a futuro de la acción. Dicha ética abarca al campo de todos los efectos colaterales y retroacciones posibles generados por la acción. De esa manera, la RSC parte de una visión sistémica y holística del entorno de las personas (Vallaeys, 2011).

En el desarrollo de la comunicación del destino turístico, teniendo en cuenta el paradigma de la RSC, el papel que juegan el público de interés o stakeholders es fundamental, ya que actúan definidos bajo el principio de la interdependencia; es decir, el éxito organizacional se debe en parte a las elecciones y acciones de estos grupos que tienen un interés en y hacia la organización o destino turístico (IESE Business School, 2009). El termino stakeholders está vinculado a los que Buhalis (en Bigné, et. al, 2000) denomina actores del destino. Por su parte, Puterman (2011) expresa que para mostrar el marketing responsable la publicidad o comunicación de una organización debe ser clara y sin omisiones.

Respecto a la comunicación de crisis de los destinos (CDC), definiremos los desastres o crisis de acuerdo a la nomenclatura sugerida por el Foro Económico Mundial (WEF, 2015), el cual menciona la existencia de cinco tipos de desastres:

\section{- Económicos}

- Medioambientales (terremotos, erupciones volcánicas.)

- Geopolíticos (guerras, terrorismo)

- Sociales

- Tecnológicos

EI WEF señala, además, que estos tipos de desastres pueden provocar grandes impactos en el sector turístico, debido al carácter global e intersectorial de la actividad. Tanto la Organización Mundial del Turismo (OMT) (1980) como diversos autores (Young \& Montgomery en Muñiz, 2010); Wilks \& Moore, 2003; Faulkner, 2001) coinciden en que es cada vez más necesario el diseño de modelos o marcos para la gestión de crisis en destinos con el fin de acelerar el proceso de recuperación integral de los mismos. En el contexto de desastres, la gestión de crisis se define como las acciones llevadas a cabo en respuesta a una situación de crisis, comprendiendo un proceso integral teniendo como principal objetivo salvaguardar a la comunidad ante una situación de inestabilidad (Vega Fernández, 2006). De allí que se considere de suma importancia la gestión de crisis en turismo especialmente en la última década en que situaciones o eventos críticos han afectado fuertemente a diversos destinos turísticos a nivel mundial.

Según la OMT (2012), un elemento de importancia para un correcto sistema de gestión de crisis es la comunicación que debería estar orientada a reducir el impacto negativo de las comunicaciones de forma eficiente, puntual y responsable, ante la necesidad de informar a todas las partes interesadas: "limitar el impacto negativo de una crisis al afrontar las necesidades de información de todas las partes interesadas de manera eficiente, puntual y responsable" (OMT, 2012, p.viii). 
Al respecto, ha diseñado documentos específicos que presentan herramientas de comunicación de crisis en el ámbito del turismo para Organizaciones Nacionales de Turismo (ONT), Organizaciones de Gestión de Destinos (OGD) y entidades del sector privado relacionadas con los viajes y el turismo (OMT, 2012, p.4). Los mecanismos incluyen protocolos y directrices a seguir para medir su eficacia. Comprende, además, prácticas recomendadas y un manual de uso de medios sociales para momentos de crisis. En resumen, existen cuatro principios que deberían sostener la gestión de crisis en turismo (Pender \& Sharpley, 2005):

1. Coordinación. Gestión de crisis con un enfoque de coordinación entre lo público y lo privado. Esto implica establecer un apropiado grupo de manejo de crisis estableciendo roles puntuales para cada eslabón.

2. Colaboración. Todos los actores del destino deben trabajar con base en el principio de colaboración, tratando de eliminar conflictos que puedan surgir entre los diferentes organismos en tiempo de crisis.

3. Comunicación. Debe organizarse un centro de comunicación de crisis que concentre la información de lo que está sucediendo. La imagen dañada del destino puede amenazar la sostenibilidad del turismo y poner en peligro la viabilidad económica a largo plazo. Teniendo en cuenta la habitual respuesta negativa de los turistas a las crisis, el énfasis debe ponerse tanto a corto como en el medio plazo en la promoción y la comunicación.

4. Compromiso. Todas las partes deben estar comprometidas con el manejo de crisis y sobre todo estar preparadas y ser conscientes de que una crisis puede llegar a suceder en cualquier destino y en cualquier momento (Figura 3).

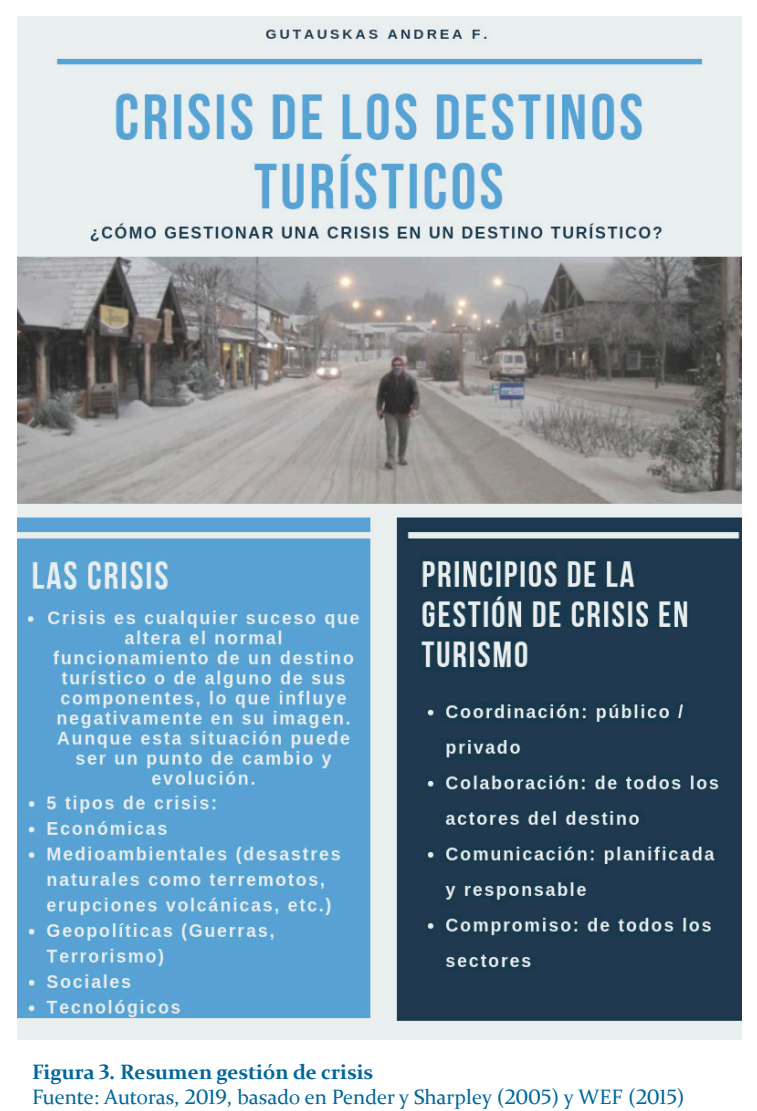

Además de los principios mencionados Young y Montgomery (citado por Muñiz, 2010) presentan compilaciones de procedimientos y prácticas de gestión de crisis, estableciendo pautas que puedan contribuir a una más rápida y eficiente recuperación del destino luego de una crisis. Wilks y Moore (2003) presentan un modelo de gestión de riesgos y crisis de un destino turístico, llamado Modelo de las 4R's e ilustrado en la Figura 4. 


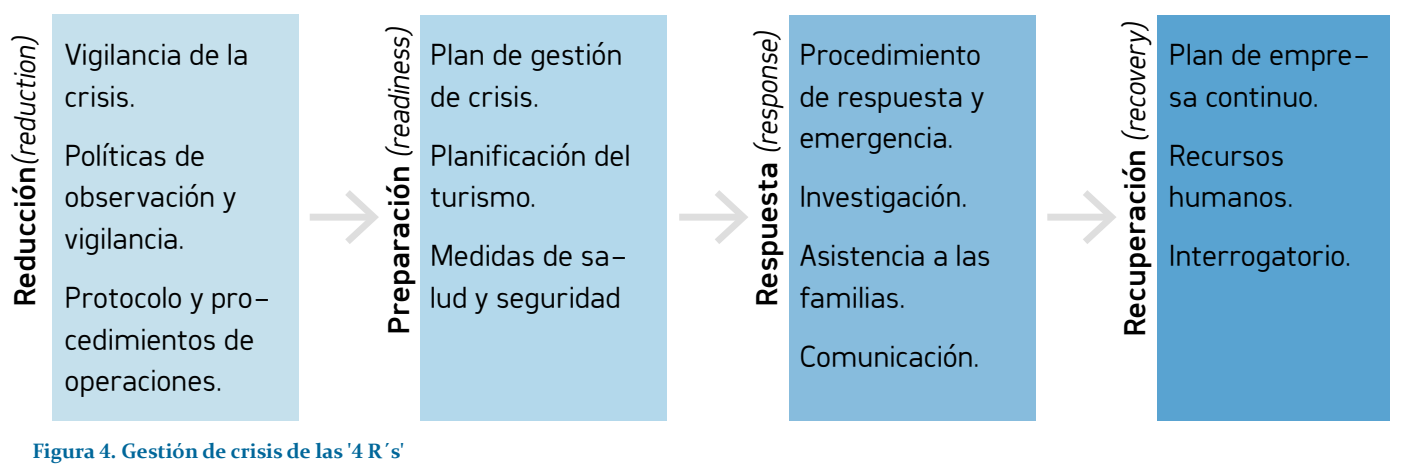

Figura 4. Gestión de crisis de las '4 R's'

Fuente: Autoras, 2019, basado en Wilks y Moore (2003)

Las fases de reducción y preparación son previas al impacto y deben detectar las primeras señales de amenaza (reducción), realizar la planificación y formar a las personas en la gestión de crisis (preparación). En la fase de respuesta se ejecutan las operaciones y planes de comunicación en una situación de crisis. Por último, se desarrolla la fase de recuperación cuyo fin principal es la restauración del destino u organización y se procura el retorno a la normalidad.

Otros estudios realizados identificaron la falta de atención a los aspectos creativos del mensaje publicitario en situaciones de crisis (Torres Romay, 2009). Ello puede deberse a factores como la premura en la organización de la respuesta a la crisis -las primeras 24 horas son decisivas- así como también a la necesidad de transmitir una mayor información que en una campaña comercial planificada.

Las crisis se producen por una serie de circunstancias que concurren en un determinado momento y suponen un cambio de situación que pone en peligro la imagen y el equilibrio natural de una organización (Piñuel citado por Torres Romay, 2009). Por lo tanto, la comunicación, originada en la organización destinada al mercado, debe comprenderse desde el punto de vista social, económico e incluso político. Los autores mencionan que, a pesar de los avances realizados en la aplicación de CDC, sus preceptos teóricos no han evolucionado al mismo ritmo, especialmente en lo que se refiere a qué instrumentos comunicativos son los más convenientes de aplicar, con el fin de contribuir a mejorar la comunicación en tiempos de crisis.

Por último, hablaremos de la resiliencia comunitaria y de imagen. La expresión 'resiliencia', utilizada en ingeniería, y hace referencia a la capacidad de un "material para alcanzar su forma primera después de soportar una presión que lo deforme" (Acevedo, 2002, p.12). Al vincular el término resiliencia con los seres humanos se define como la "capacidad de una persona o de un sistema social de vivir bien y desarrollarse realmente, a pesar de las difíciles condiciones de vida y más aún, de salir fortalecidos y ser renovado por ellas" (Acevedo, 2002, p.12).

Acevedo (2002) introduce el término de 'resiliencia comunitaria', ya que la vida en comunidad es una exigencia interna el ser humano, y significa intercomunicación afectiva, siendo la base del crecimiento humano. En comunidad, el ser humano crea lazos con base en la confianza y el afecto, pero también para atender al dolor, acercarse en los momentos de angustia y apoyarse para dar esperanza. La resiliencia comunitaria se ha aproximado a la concepción de comunidades saludables como un nuevo instrumento para obtener equidad social y lograr un desarrollo positivo, teniendo en cuenta las metas de la propia cultura. El autor menciona los factores que favorecen la resiliencia comunitaria: autoestima colectiva, sentido de comunidad, identidad cultural, 'vincularidad' (redes de apoyo), ideales, equidad social, liderazgo y honestidad. Como elementos negativos destaca: malinchismo (admiración obsecuente de todo lo extranjero), fatalismo, autoritarismo y corrupción administrativa.

Vinculando el concepto de resiliencia con las marcas turísticas y teniendo en cuenta lo expresado por Ledhesma (2017), la resiliencia puede considerarse como el acto y el proceso de superar la adversidad para volverse una marca más fuerte, madura y resistente en el tiempo. Esto se logra, combinando factores como vínculos honestos entre los creadores de la marca y su público, siendo capaces de recibir y dar ayuda, no actuar impulsivamente, tener confianza en los propios valores de la marca y en la propia capacidad del conjunto de personas involucradas, estableciendo objetivos claros y concretos, buscando el autoconocimiento constante, y entendiendo y aceptando que el cambio y la crisis son partes necesarias del ciclo de vida de las marcas. 


\section{DISEÑO METODOLÓGICO DE LA INVESTIGACIÓN}

Para dar respuesta a los objetivos planteados y los interrogantes planteados se llevó a cabo una investigación descriptiva, aplicando una triangulación metodológica o método mixto cualitativo -cuantitativo (Tashakkori \& Teddlie, 1998; Creswell \& Clark, 2007) a través de la aplicación de distintas herramientas de recolección de datos:

- Análisis de contenido aplicado a artículos periodísticos como unidades de análisis. Fueron seleccionados a partir de la apreciación de texto y contexto, considerando como la unidad de publicación el artículo periodístico y elegidos en función del concepto 'inclusión por relación' (Mantero et al., 2003). Fundamentado por el hecho de que el análisis de contenido es un rico y vasto campo para la investigación científica (Mendes da Rocha Neto et al., 2010). Se analizaron 782 noticias sobre la crisis de VLA publicadas en diarios impresos regionales (diarios La Mañana del Sur y Río Negro, siendo los dos únicos diarios impresos de la zona), nacionales (diarios Clarín, Nación, Pagina 12, por ser los de mayor número de tirada) y medios en línea (sitio web oficial de prensa del Gobierno de la Provincia del Neuquén, elegido por ser la principal voz oficial) publicadas entre 29 de mayo de 2010 y 03 de Julio de 2012. La elección de dichos medios se fundamenta en que se hizo un recorte de medios en función de la posibilidad de almacenamiento de las noticias escritas y la accesibilidad a los mismos.

- Sondeo de opinión en la temporada de verano de 2012. Se obtuvo una muestra de 130 individuos a través de Internet mediante un muestreo intencional a contactos de la red social Facebook para indagar acerca del conocimiento de la erupción del volcán, la imagen de VLA posterior a la crisis y la propensión a la elección de VLA como próximo destino turístico.

- Entrevistas en profundidad (Malhotra, 2008) a los responsables de los organismos de turismo a nivel provincial y municipal con el objetivo de hacer una revisión y descripción de las acciones de comunicación que se llevaron a cabo pos-evento del destino turístico VLA.

\section{RESULTADOS}

\section{Imagen del destino proyectada por agentes autónomos}

De los 782 artículos periodísticos analizados se pudo conocer la imagen proyectada por los agentes autónomos. El 90,52\% de las noticias analizadas se concentraron durante el evento del volcán (junio-diciembre 2011), le siguen las publicadas desde enero 2012, y hasta un año después del suceso con el 6,6\%. Del total de artículos estudiados, el 76\% corresponde a diarios impresos y el $15 \%$ a medios en línea (ver Figura 5). El 38\% de las noticias publicadas en diarios impresos corresponden al diario La Mañana del Neuquén y el 34\% al diario Río Negro. En menor medida corresponden a diarios impresos de alcance nacional: el 9\% a La Nación, un 7\% a Clarín y un 13\% corresponde a noticias de otros diarios -como Página 12, Ámbito Financiero, El Cronista Comercial, Infobae y La Nueva Provincia. Respecto de la ubicación de las noticias en los medios impresos, el $62 \%$ de las noticias se sitúan en páginas interiores del diario y el $15 \%$ corresponden a noticias de la portada (ver Figura 6).

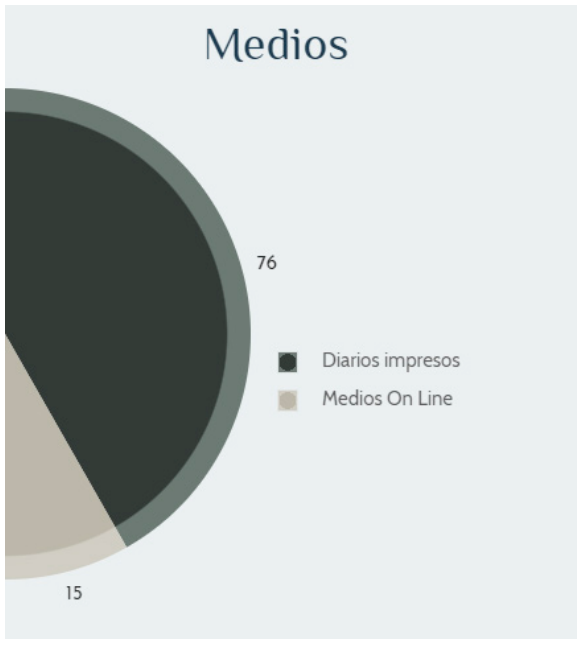

Figura 5. Tipo de medio periodístico de la noticia analizada Fuente: Autoras, 2019

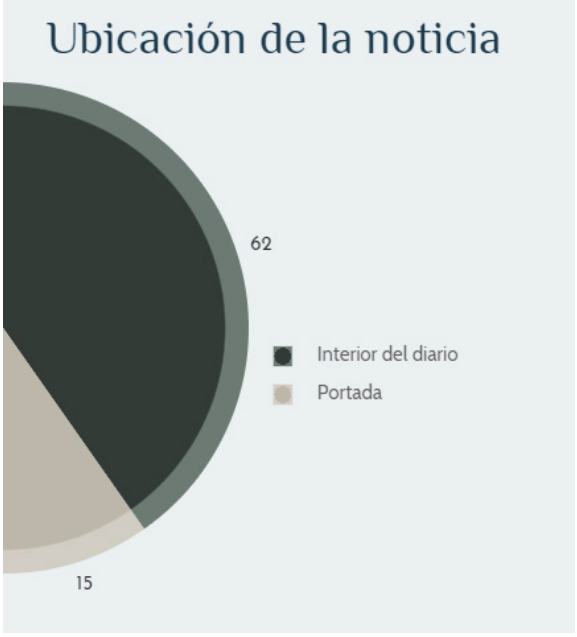

Figura 6. Ubicación del artículo - medios Impresos Fuente: Autoras, 2019 
En cuanto a los medios en línea, el 69\% son noticias del Boletín Informativo del Gobierno de la Provincia del Neuquén, el 19\% a diarios turísticos en línea (Diario Andino, Host News, La Angostura Digital), el 7\% de publicaciones de Facebook (de los sitios oficiales de Turismo de la Provincia, del destino y del centro de esquí Cerro Bayo). El 53\% de las noticias usan la palabra 'VLA'. Las palabras mas utilizadas en el texto de la noticia son en primer lugar 'VLA' y 'cenizas' con mucha importancia en cantidad de veces que aparecen. En menor medida se utilizan las palabras 'emergencia', 'Volcán-Puyehue', 'desastre'. Otras palabras mencionadas fueron: 'vuelos' y 'no vuelos', 'erupción', 'ayuda', 'emergencia económica', 'emergencia social'.

Previo a la erupción del Volcán Puyehue, los títulos hacen referencia al paisaje, a las vacaciones, al lujo, al placer. Las palabras utilizadas en las noticias remiten a los atributos del destino en cuanto a su entorno natural, a través de expresiones como: 'jardín de la Patagonia', 'paisaje privilegiado', 'lugar paradisíaco', 'espejo de agua', 'cascada'. También se apela a componentes afectivos que los visitantes expresan del destino: emoción, bienestar, encanto (ver Figura 7).

Durante la crisis, los títulos hacen referencia a las cenizas y a la situación de emergencia. Algunos títulos se refieren a la solidaridad mostrada por numerosos voluntarios que colaboraron durante la emergencia. Progresivamente, comienzan a aparecer títulos que vislumbran la recuperación como 'plan de promoción turística', 'tenacidad para resurgir' 'recuperar la Angostura'. Entre las palabras que describen la situación vivida en el destino se señalan: 'situación crítica', 'erupción', 'cancelaciones', 'restricciones al tránsito', 'paisaje gris', 'ayuda', 'pérdida', 'limpieza', 'reinventarse', 'renacer'. Finalmente en la etapa pos-crisis los títulos reflejan cómo la comunidad se recupera de la situación. Esto se sintetiza a través de titulares como 'un año después la Angostura renace' apelando a términos como 'festejo', 'esperanza', 'odisea', 'recuperación', 'turistas', 'vocación turística', 'recuperación de colores'. Utilizando el método Nube de Palabras, la Figura 7 sintetiza los principales resultados sobre los titutlares en los medios: antes, durante, y después de la crísis.

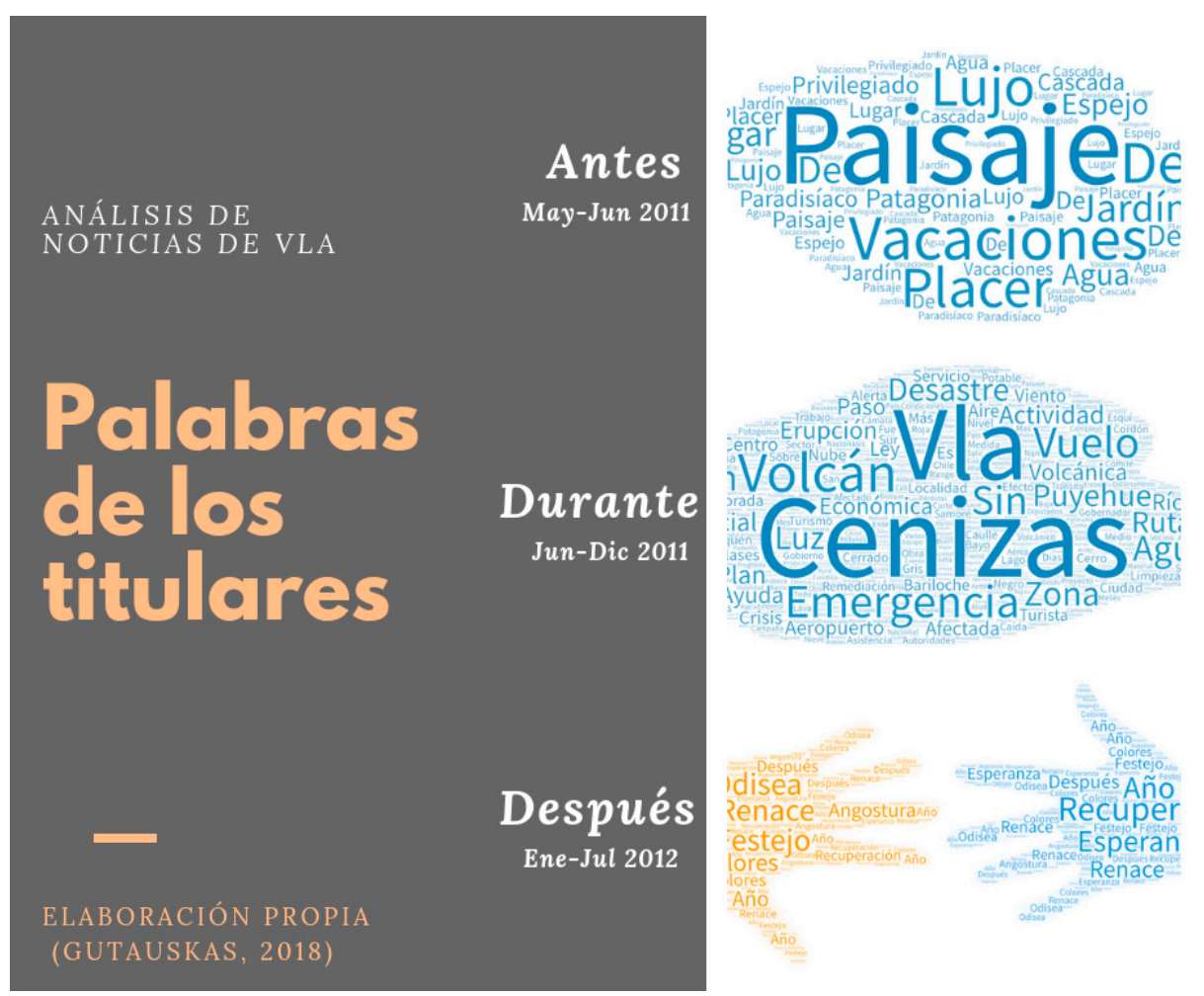

Figura 7. Principales palabras utilizadas por las noticias analizadas Fuente: Autoras, 2019

Analizando si la noticia era acompañada de una imagen, se obtuvo que el $73 \%$ no la utilizó. Para aquellos artículos periodísticos que la contenían, se realizó un análisis de las mismas teniendo en cuenta la fecha del artículo. Las noticias previas al 4 de junio de 2011 contenían fotografías relacionadas a los atractivos de VLA, como el muelle, el lago, montañas y bosques. Desde el 4 de junio de 2011 y hasta junio de 2012, las imágenes muestran el destino y sus atractivos cubiertos del 
gris de las cenizas. Las primeras fotografías corresponden a las consecuencias directas del suceso y trasmiten el desconcierto de los habitantes como así también de las autoridades municipales. Posteriormente, se puede ver que algunos artículos periodísticos -especialmente de organismos públicos provinciales y municipales- transmitían otra visión del destino como de las reuniones del comité de emergencia de VLA y de las autoridades al aire libre y con un día soleado, del lugar transformándose y volviendo a su normalidad.

A partir de julio 2012, se visualiza el uso de imágenes dispares. En algunos casos, comparan VLA durante y después del suceso del volcán, es decir VLA con cenizas y VLA sin cenizas. En otros casos, las fotografías mostraban a VLA limpia sin cenizas o a operarios de los distintos organismos realizando tareas de limpieza como así también de VLA con nieve. Todas las imágenes enfatizan la recuperación del destino.

\section{Imagen posterior a la crisis y propensión a la elección del destino: a partir del 4 de junio de 2011 y hasta la temporada invernal 2012}

A continuación, se describen los resultados del sondeo de opinión realizado a 130 personas, el $70 \%$ de los encuestados eran residentes de las provincias de Neuquén y Río Negro pero, también, aunque en menor medida, se obtuvieron respuestas de encuestados con residencia en otras provincias de Argentina como Córdoba, Mendoza, Buenos Aires, San Juan, Capital Federal, Santa Fe, principalmente de sexo femenino (72\%) y en su mayoría (80\%) mayores de 31 años. El $78 \%$ había visitado VLA con anterioridad al sondeo y el 22\% había escuchado del destino (ver Figura 8).

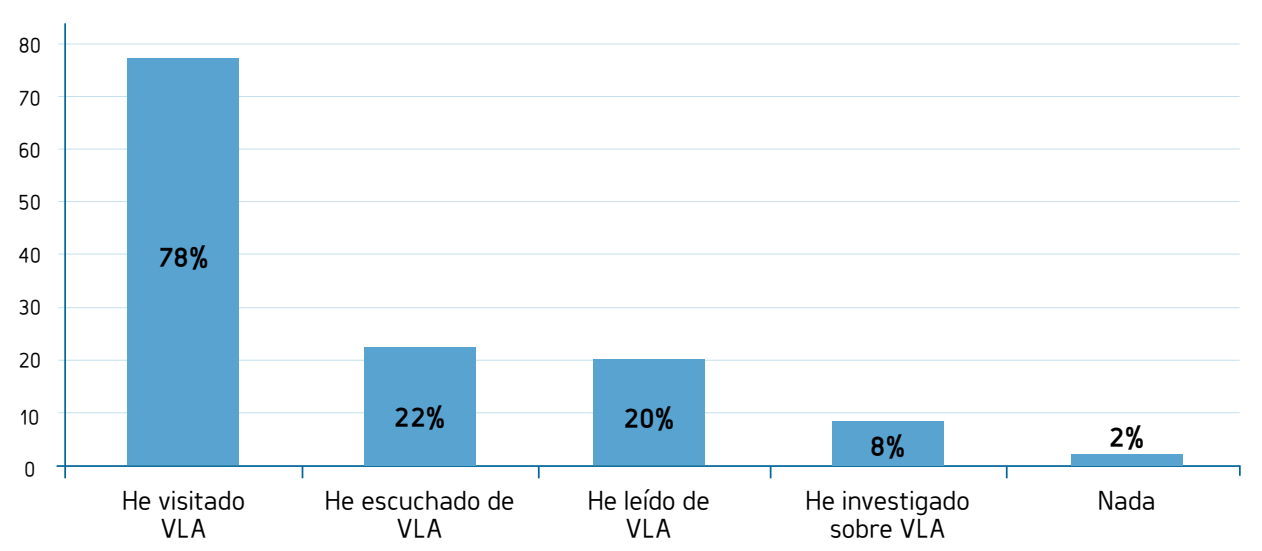

Figura 8. Conocimiento previo del destino VLA Fuente: Autoras, 2019

En cuanto a si los encuestados conocían o habían oído del suceso del volcán, el 95\% contestó afirmativamente. El $94 \%$ indicó que siguió las noticias del volcán (ver Figura 9 y 10).

Entre los medios que fueron utilizados para conocer o seguir las noticias del volcán Puyehue, fueron mencionados los diarios regionales $(29,41 \%)$, los diarios en línea $(19,85 \%)$ y las redes sociales $(18,38 \%)$. Además, a los entrevistados se les planteó una serie de afirmaciones que tenían que ver con los efectos directos de la erupción del Volcán Puyehue sobre el destino turístico en estudio. Frente a las afirmaciones presentadas los encuestados debían consignar su grado de acuerdo o desacuerdo, obteniendo que el $52 \%$ estuvo en desacuerdo con "La ciudad de VLA estaba cubierta de ceniza del Volcán”; el 60\% consideró que los servicios básicos del destino funcionaban correctamente. Se pudo ver una dispersión en las respuestas en cuanto a la afirmación que VLA estaba limpia y totalmente verde; solo el $21 \%$ estuvo totalmente de acuerdo. El $52 \%$ de los encuestados consideró que el mencionado destino era seguro para el turismo. El 38\% indicó que el evento del volcán Puyehue no modificó la imagen que tenía del destino, aunque un $21 \%$ consideró estar de acuerdo con que el evento del volcán cambió su imagen del destino. El 47\% de los encuestados consideró que no elegiría a VLA como destino de viaje para sus próximas vacaciones -verano de 2012. De esta manera, se puede ver la influencia psicológica de las noticias en la elección del próximo destino de viaje.

En cuanto a las palabras que surgían a la mente al momento de mencionar a VLA, se mencionaron con más frecuencia 'desastre', 'Desastre-Natural', 'Irrecuperable', 'SolidaridadPobladores', 'Devastador'. Otras palabras surgidas son 'Ceniza' 'Todo Gris', 'Problemas con la fauna', 'Desconcierto', 'Daño', 'Arruinada', 'Angustia, tristeza, desolación y oscuridad'. 


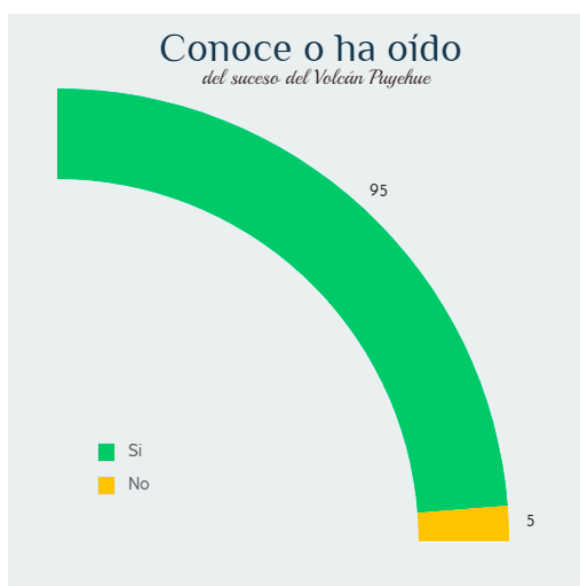

Figura 9. Conoce o ha oído del suceso del Vvolcán Puyehue Fuente: Autoras, 2019

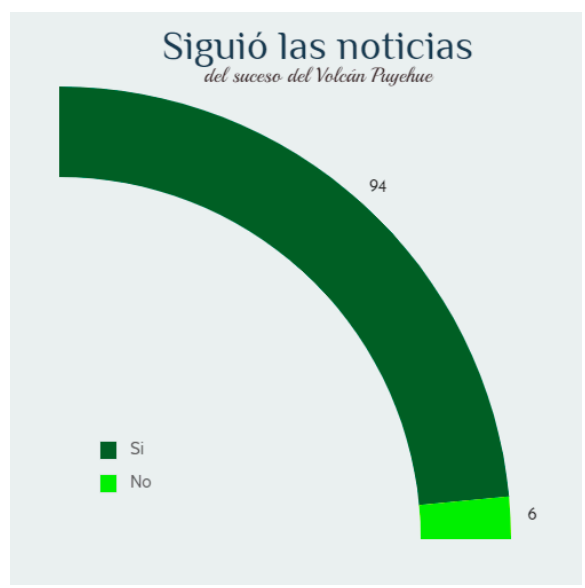

Figura 10. Siguió las noticias del suceso del Volcán Puyehue Fuente: Autoras, 2019

\section{Acciones de comunicación desde el destino pos-crisis}

Como resultados de las entrevistas en profundidad y del análisis de entrevistas en diarios regionales a responsables de las áreas de turismo vinculadas al destino VLA, se pudo ver la preocupación que significó el evento del volcán Puyehue desde distintos ángulos. Por un lado, la 'No llegada de turistas'. En declaraciones públicas, el Secretario de Turismo de VLA comentó que:

"Todos los números que podamos hacer de la temporada anterior (2011) son negativos; fue el peor año de la historia para nosotros. Lo que hacemos es una proyección futura basada en percepciones de que vamos cada vez mejor. El primer semestre de 2012 nos da positivo".

(Diario InfoBae, 2012)

Según el informe de NeuquenTur (octubre 2012), se estimó que durante junio de 2011 se utilizaron más de $\$ 12$ millones de pesos argentinos en publicidad negativa del destino, correspondientes a los artículos periodísticos de diarios regionales y nacionales.

El cambio en la imagen del destino VLA se produjo como efecto directo de las repercusiones que tuvieron las noticias - generadas por agentes autónomos- en los mercados y que son 'no controladas' por el destino, como así también las expresiones de los propios pobladores -que tuvieran relación directa o indirecta con el turismo- brindadas a través de entrevistas a los medios.

Además, la celeridad de los acontecimientos hizo que se tuvieran que reprogramar todas las actividades de comunicación y promoción del destino y enfocarse en el armado de un plan de contingencia 'Angostura Podemos'. El mismo fue elaborado por el Estado Provincial (Subsecretaría de Turismo y NeuquénTur) en conjunto con el Estado Nacional (Ministerio de Turismo de Nación), los Estados municipales afectados (Secretarías de Turismo de VLA y de San Martín de los Andes y Comisión de Fomento de Villa Traful) y cámaras hoteleras de los destinos, teniendo como base una fuerte interrelación de los sectores público y privado. Para la ejecución del plan se trabajó con socios estratégicos, especialmente organismos provinciales como Lotería La Neuquina, Banco Provincia del Neuquén y el Consejo Federal de Inversiones. El plan tuvo como objetivo principal impulsar un reposicionamiento gradual de la región que debía complementarse con las acciones de recomposición de los destinos turísticos. Aspecto de vital importancia para superar las noticias negativas.

Los actores del sector público y privado del destino concordaron en la necesidad de generar acciones conjuntas de comunicación y promoción del destino que permitieran sostener a las Microempresas, y Pequeñas y Medianas Empresas (MPyMES) turísticas y así lograr mejorar los niveles de ocupación y restablecerlos a lo habitual. Además, coincidieron en que la temporada invernal 2011 estaba perdida para el destino VLA, en que en los otros destinos afectados por la crisis del volcán Puyehue solo se podía mitigar la caída de demanda y en que había que enfocarse en la temporada de verano 2012. Teniendo en cuenta lo antes descripto, las acciones de comunicación sobre las que se trabajaron fueron:

- Mitigar el deterioro de la imagen del destino durante la erupción. 
- Diferenciar comunicacionalmente la situación de los distintos destinos pero, a la vez, evitar que esa diferenciación se haga sin mostrar los problemas que estaban viviendo los destinos más afectados

También fueron necesarias otras acciones como lograr que el destino VLA esté operativo para la temporada estival, finalizar la limpieza del ejido urbano de VLA en 12 meses y recuperar la conectividad terrestre con Chile y la conectividad aérea en la región.

Uno de los ejes de acción del plan fue la recomposición y revalorización de la imagen del destino turístico, para lo cual se ideó un plan de marketing de contingencia. En él, se estableció concentrar las acciones en pocos mercados, de los más cercanos a los más lejanos, y en los productos que generaban más movimiento de turistas y más derrama económica. Así, se definieron los mercados prioritarios: Alto Valle, Área Metropolitana de Buenos Aires, Rosario, Córdoba, Provincia de Buenos Aires (Mar del Plata, Bahía Blanca), las regiones chilenas del Maule, La Araucanía y Los Lagos, y Brasil. Los productos principales sobre los que se armó el plan de marketing fueron: invierno (esquí / nieve) y primavera/verano (pesca, turismo aventura).

Las acciones puntuales de marketing llevadas a cabo por el plan de contingencia fueron: auspicio de eventos, fam press, acciones cooperadas con medios regionales, organización de eventos, acciones promocionales, publicidad en medios tradicionales, publicidad en la vía pública (en los destinos considerados prioritarios), fam tours, acciones de marketing digital, ferias regionales, nacionales e internacionales.

Como resumen de las acciones de prensa, en total fueron: 320 gacetillas difundidas, 2.190 notas recopiladas, 63 medios recibidos y 127 periodistas atendidos en la región. Como indicador de control o resultados de las acciones llevadas a cabo, se tomaron los datos de la temporada invernal 2012, que tuvieron un crecimiento total de los visitantes que durmieron en los alojamientos de VLA en un $20 \%$ con respecto del promedio del índice de ocupación hotelera desde 2005 y hasta 2010 (NeuquenTur, 2012).

\section{PRINCIPALES CONCLUSIONES}

La imagen previa de VLA por parte de la demanda se corresponde con la definición de destino presentada en el marco teórico, ya que los encuestados mencionaron al destino como un conjunto de experiencias y de servicios más allá de un lugar geográfico. Dicha imagen previa se contrapone ampliamente con aquella mencionada por la demanda luego del suceso del volcán, visiblemente influenciada por los agentes autónomos, definida con las palabras 'desastre', 'tristeza', 'todo gris'.

El papel de los agentes inducidos abiertos y orgánicos en las situaciones de crisis de los destinos es considerado de suma importancia particularmente en el caso de VLA ya que las principales noticias de lo sucedido fueron emitidas por diarios regionales pero un porcentaje importante correspondieron a diarios nacionales cuyo alcance, teniendo en cuenta el avance tecnológico de hoy en día, no se limita solamente a Argentina, sino que llega a todo el mundo. Esta afirmación puede corroborarse a través del resultado obtenido por el sondeo de opinión realizado, según el cual, del alto porcentaje de encuestados que mencionaron haber conocido o escuchado del suceso del volcán, el $89 \%$ manifestó haber seguido las noticias y la mayoría mencionó que lo hizo a través de diarios regionales, diarios en línea y redes sociales.

Además, se debe mencionar que, si bien el mayor porcentaje de los artículos periodísticos corresponden a noticias ubicadas en el interior de los diarios, hubo un porcentaje mínimo (del 15\%) de las mismas que se publicaron en las portadas, pero aun así son las que han quedado grabadas en la mente de las personas al definir la situación del destino.

La mayoría de las noticias usaban el término VLA, y como palabras más utilizadas se mencionan 'emergencia', 'desastre', 'cenizas' y 'desastre natural', claramente elegidas también por la demanda al describir la imagen de VLA luego del suceso del volcán.

Lo mencionado se complementa con la comparación realizada de los títulos utilizados o publicados por los medios antes y luego del suceso del volcán, surgiendo las mismas palabras.

Se visualiza la falta de control por parte de destino turístico del accionar de los medios autónomos de comunicación, en la emisión de la información, sobre todo en un momento de crisis, donde lo inmediato traspasa lo planificado. Se observa también que en estas situaciones fue muy difícil ponerse de acuerdo y trabajar bajo los principios de una gestión de crisis, debido a la inmediatez, dificultando el control de los agentes orgánicos e inducidos. 
A medida que transcurre la situación de crisis se deberían articular las acciones con base en los principios de coordinación, colaboración, comunicación y compromiso. En este hecho particular del destino VLA, es posible visualizar la aplicación de estos principios en la respuesta de los distintos actores del destino, en principio con la organización del Comité de Emergencia, encargado no solo de la recuperación física del destino sino también de la organización de la comunicación e información a emitir para revertir la imagen dañada del destino. De no haberlo hecho la crisis hubiera tenido efectos catastróficos en lo social, lo económico y lo político a largo plazo.

Haciendo revisión de otros casos de comunicación en crisis y en base a la propia experiencia vivida en el destino, esta situación supone una posición yuxtapuesta en la que por un lado la palabra VLA estuvo en la mente de las personas logrando un posicionamiento (no positivo), pero a la vez si esta situación se utiliza positivamente por parte de los agentes de los destinos se podría ver como una oportunidad, considerando esto como parte de la resiliencia comunitaria. Se pudo visualizar la alta autoestima colectiva, el sentido de comunidad, la identidad cultural y la 'vincularidad'.

La situación de crisis es un reto muy importante para los actores del destino, y de los cuales se identificó su activa participación, tanto del sector público -es este caso a nivel municipal: la Secretaría de Turismo, a nivel provincial; la Subsecretaría de Turismo y el Ente NeuquenTur, a nivel nacional; el Ministerio de Turismo de Nación-, del sector privado -prestadores de servicios turísticos y cámaras empresarias-, de la comunidad local y de los turistas. Las actuaciones de todos ellos fueron fundamentales para el restablecimiento de las condiciones del destino como así también en la proyección de la imagen del mismo.

Las interacciones entre los mencionados actores del destino, permitieron avanzar y resolver las últimas fases del modelo de gestión de crisis 4 R's de forma exitosa, ya que hoy en día tanto la imagen del destino VLA como la actividad turística están totalmente recuperadas, comprobado con las estadísticas oficialmente 2012.

Por otro lado, se visualiza, que la falta de un procedimiento a seguir en casos de crisis hace más difícil el control de la comunicación que se emite desde el destino. Esto hace resaltar la importancia de lo vivido por la comunidad de VLA durante esta crisis provocada por un evento natural como la erupción del volcán, que debería tomarse como un aprendizaje o experiencia a tener presente para trabajar en la gestión de las dos primeras etapas del modelo de las 4 R's, como son la 'reducción' o vigilancia de la situación y de 'preparación' o armado de protocolos y procedimiento en los que estén involucrados todos los actores del destino.

En situaciones de crisis, vale la aplicación de la comunicación bajo la ética responsable, es decir, informar lo que realmente está sucediendo y de la forma más veraz posible. Pero también ir mostrando la recuperación del destino y los efectos positivos que produce para cada uno de los stakeholders participantes del mismo. Los organismos públicos debe establezcan pautas para la aplicación de estrategias de comunicación responsable de la imagen de los destinos turísticos que contrarresten la imagen post crisis.

Como conclusión general se destaca la necesidad de que los destinos turísticos incorporen planes de gestión de crisis tanto en sus planes de desarrollo como en las estrategias de marketing y de gestión, especialmente centrados en el desarrollo sostenido y la comunicación responsable. Lo que repercutirá en contar con un protocolo de acción frente a nuevas situaciones de crisis que permitan (Sönmez et al., 1999):

- Proteger y reconstruir la imagen de destino seguro y atractivo

- Asegurar la llegada de turistas a un área segura

- Restablecer el atractivo y las operaciones del destino

- Ayudar a la recuperación económica del sector turístico

A modo de síntesis, se recomienda que los planes de gestión de crisis de turismo deben centrarse en indicar los pasos que se deben seguir en dichas situaciones como: conformación inmediata de un comité o grupo de trabajo, quiénes deben integrar este grupo, cuáles son las responsabilidades de los integrantes, quién debe realizar las tareas de coordinación, debe sugerir una lista de indicadores de control previos y posteriores al desastre. Además, debe contar con un protocolo 
de acción de comunicación a utilizar en estas situaciones conteniendo directorio de contactos, principales acciones de comunicación a implementar de forma inmediata, debe sugerir qué hacer y qué evitar en cada herramienta de comunicación a utilizar, entre otras acciones.

Como experiencia de este proceso de investigación destacan algunos últimos aspectos: la escasa cantidad de bibliografía encontrada sobre 'responsabilidad social empresaria' referida específicamente a destinos turísticos. La intención del presente trabajo fue lograr una base documental del suceso del volcán Puyehue y su repercusión en un destino turístico, dando un puntapié a nuevas líneas de investigación que permitan profundizar o ampliar el conocimiento del tema en el futuro.

\section{REFERENCIAS}

Acevedo, G. (2002). Logoterapia y resiliencia. Nous, (6), 23-40.

Beerli, A., \& Santana, M. (2003). La formación de la imagen de los destinos turísticos a través de los factores internos del turista. En 6o Congreso de Turismo Universidad y Empresa. Turismo Cultural y Urbano. Castellón de la Plana - España. Octubre 2003.

Bigné, J. E., Font, X., \& Andreu, L. (200o). Marketing de destinos turísticos: análisis y estrategias de desarrollo. Madrid: ESIC.

Buhalis, D. (2000). Marketing the competitive destination of the future. Tourism Management, 21(1), 97-116.

Creswell, J. W., \& Clark, V. L. P. (2007). Designing and conducting mixed methods research. San Francisco, California: SAGE Publications.

Diario InfoBae. (agosto 2012). Villa La Angostura se pone de pie a un año de la erupción del volcán Puyehue. Diario InfoBae [online] Recuperado de: http://www.infobae.com/2012/o6/o4/651369-villala-angostura-se-pone-pie-un-ano-la-erupcion-del-volcan-puyehue [visitado el 2 de Feb. 2019]

Dirección Provincial de Estadística y Censos de la Provincia del Neuquén. (2001). Censo Nacional de Población, Hogares y Viviendas 2001. Neuquén: CPN. Recuperado de: http://www. estadisticaneuquen.gob.ar/poblacion_composicionYdistribucion.html [visitado el 5 de Mar. 2015]

Echtner, M., \& Brent Ritchie, J. R. (2003). The Meaning and Measurement of Destination Image. The Journal of tourism studies, 14(1), 37-48.

Escalera Reyes, J. \& Ruiz Ballesteros, E. (2011). Resiliencia Socioecológica: aportaciones y retos desde la Antropología Socioecological. Revista de Antropología Social, 20, 109-135.

Evans, N., \& Elphick, S. (2005). Models of crisis management: an evaluation of their value for strategic planning in the international travel industry. International Journal of Tourism Research , 7(3), 135-150.

Faulkner, B. (2001). Towards a framework for tourism disaster management. Tourism Management, $22(2), 135-147$.

Gartner, W. C., \& Hunt, J. D. (1987). An analysis of state image change over a twelve-years period, Journal of travel Research, 26(2), 5-19.

Gartner, W. C. (1994). Image Formation Process. Journal of Travel E Tourism Marketing, 2(2-3), 191-216.

Gutauskas, A., \& Valdez, R. (2014). Comunicación Responsable de Marcas Turísticas: Caso de estudio Villa la Angostura (VLA). En Campodonico, R., Rosake, P. \& Ercolani, P. (Eds.), Libro de Actas VI Congreso Latinoamericano de Investigación Turística. Neuquen: Educo.

IESE Business School. (2009). La Evolución del Concepto de Stakeholders en los escritos de Ed Freeman. En University of Navarra (Ed.) Newsletter no ${ }^{-}$-.Otro punto de vista. Navarra: University of Navarra, 1-4.

Jick, T. D. (1979). Mixing qualitative and quantitative methods: Triangulation in action. Administrative science quarterly, 24(4), 602-611.

Ledhesma, M. (2017). Gestión de crisis en turismo. Buenos Aires: Miguel Ledhesma.

Madrid Peralta, A. (2011). Análisis Comparativo de Experiencias Internacionales Exitosas sobre Reconstrucción Productiva en Destinos Turísticos Afectados por Desastres y Situaciones de Crisis, Revista Patrimonio Turístico en Iberoamérica, 43-54

Malhotra, N. (2008). Investigación de Mercado (5ta ed.). Ciudad de México. Pearson Educación.

Mantero, J.C., Manzo, M., Murashima, N., Wesner, M.E. \& Alegre, P. (2003). Comunicación y Prescripción de destinos y productos turísticos. Análisis de contenido de un medio de comunicación, Aportes y Transferencias, 7(2), 57-80. 
Mendes da Rocha Neto, J., Freire Borges, D., \& Furtado, E M. (2010). Entre palabras y deseos. Análisis de contenido de la publicidad de los hoteles. Estudios y Perspectivas en Turismo, 19(5), 761-775.

Mesa de Acuerdos para la sustentabilidad de VLA (2011). Documento "Presentación Plan de Recuperación integral de VLA de Junio 2011”. Villa la Angostura: Municipalidad Villa La Angostura.

Miossec, J.M. (1977). L'image touristique comme introduction à la géographie du tourisme. Annales de Géographie, 86(473), 55-70.

Muñiz, D. (2010). La Gestión de crisis en el turismo: La cara Emergente de la Sostenibilidad. Vigo: Facultad de Ciencias Empresariales y Turismo, Universidad de Vigo.

NeuquenTur. Gobierno de la Provincia del Neuquén. (octubre 2012). Recuperación de los Destinos Turísticos de la Patagonia de Los Lagos. Recuperacion de la imagen y de la demanda de los destinos turisticos de la patagonia de los lagos post erupcion del Cordon el Caulle (Volcan Puyehue). NeuquenTur [presentación].

OMT. (1980). Physical Planning and Area Developments for Tourism in the Six. Madrid: OMT.

OMT. (2012). Herramientas de comunicación de crisis en el ámbito del turismo - Listas de verificación y prácticas idóneas. Madrid: OMT.

Pender, L., \& Sharpley, R. (2005). The Managment of Tourism. Londres: SAGE Publications Ltd.

Pforr, Ch. (2006). Tourism in Post-Crisis is Tourism in Pre-Crisis: A Review of the Literature on Crisis Management in Tourism, Curtin University of Technology School of Management Working Paper Series, 1-13.

Piñeiro Chousa, J. \& Romero Castro, N. (2011). Responsabilidad Social Empresarial y resiliencia. Revista Gallega de Economía, 20(2), 1-34.

Puterman, P. (junio de 2011). ¿Cómo hacer marketing responsable? Diario Responsable [online]. Recuperado de: http://www.diarioresponsable.com/portada/destacados/13995-icomo-hacermarketing-responsable.html [visitado el 14 de Abr. 2014].

Ritchie, B. (2004). Chaos, crises and disasters: a strategic approach to crisis management in the tourism industry, Tourism Management, 25(6), 669-683

Rossi, E. (2010). Marketing Responsable. Notas en Turismo y Economía, 1(2), 83-92.

Serra Cantallops, A. (2002). Marketing Turistico. Madrir: Editorial Pirámide.

Sönmez, S., Apostopoulos, Y., \& Tarlow, P. (1999) Tourism in crisis: Managing the effects of terrorism, Journal of Travel Research, 38(1), 13-18.

Tashakkori, A., \& Teddlie, C. (1998). Mixed methodology: Combining qualitative and quantitative approaches. San Francisco, California: Sage Publications.

Torres Romay, E. (2009). La publicidad como táctica de respuesta a las situaciones de crisis, Questiones Publicitarias, 1(14), 64-78.

Tamagni, L., Zanfardini, M. \& Gutauskas, A. (2010). El Valor de Marca de Villa Pehuenia. Revista Condet "Realidad, Tendencias y Desafíos en Turismo", 8(10), 71-86.

Vallaeys, F. (2011). La Responsabilidad Social de las organizaciones. Nueva York: UNESCO \& Instituto Internacional para la Educación Superior en América Latina y el Caribe.

Valls, J.F. (1992). La Imagen de Marca de los Países. Madrid: Mcgraw-Hill \& Interamericana de España.

Valls, J.F. (2003). Las claves del mercado turístico. Cómo competir en el nuevo entorno. Bilbao: Ediciones Deusto.

Vega Fernández, E. (2006). Gestión Internacional de Crisis. Madrid: Instituto Universitario General Gutierrez Mellado de Investigacion sobre la Paz, la Seguridad y la Defensa.

World Economic Forum WEF. (2015). Global Risks 2015. Ginerba: WEF.

Wilks, J. \& Moore, S. (2003). Tourism Risk Management for the Asia Pacific Region: An Authoritative Guide for Managing Crises and Disasters. Singapore: APEC International Centre for Sustainable Tourism (AICST).

Zanfardini, M., Tamagni, L., \& Gutauskas, A. (2012). El valor de las marcas turísticas Villa Pehuenia y VLA en el mercado de Neuquén Capital. En XXIV Encuentro de Docentes Universitarios de Comercialización de Argentina y América Latina. Tandil, Argentina. Octubre 2012. 